\title{
Novas Diretrizes Curriculares Nacionais e a Formação Médica: Expectativas dos Discentes do Primeiro Ano do Curso de Medicina de uma Instituição de Ensino Superior
}

\author{
Curricular Guidelines and Medical Education: \\ Expectations of First Year Medical Students at \\ a Higher Education Institution
}

\author{
Maria Alexandra de Carvalho Meireles ${ }^{I}$ \\ Cássia do Carmo Pires Fernandes ${ }^{I I}$ \\ Lorena Souza e Silval
}

\section{PALAVRAS-CHAVE}

- Diretrizes.

- Educação Médica.

- Medicina.
${ }^{I}$ Faculdade Dinâmica do Vale do Piranga, Ponte Nova, Minas Gerais, Brasil.

"Instituto Federal de Educação, Ciência e Tecnologia de Minas Gerais, Campus Avançado de Ponte Nova, Ponte Nova, Minas Gerais, Brasil. 


\section{KEY-WORDS}

- Guidelines.

- Medical Education.

- Medicine.

Recebido em: 4/11/18

Aceito em: 13/11/18

\section{ABSTRACT}

Students' perspectives, disappointments and achievements significantly affect their learning process and the way they perceive the profession. This study evaluates the relationship between the New National Curricular Guidelines for Medicine Courses, implemented in 2014, and the expectations of first year students of a Medicine course of a private Higher Education Institution in the state of Minas Gerais, Brazil, regarding their medical training. The study was carried out using quantitative and qualitative methods, based on the application of questionnaires that addressed aspects such as the student's profile, initial motivations and expectations of their academic training, futures plans and projects in relation to the profession, and knowledge about The National Curricular Guidelines for the Medicine Course. The results for the profile of these students indicated a predominance of female students, from the interior of the state of Minas Gerais, in the 18 to 20 year age group, who entered the institution through the vestibular exam having previously taken the National Secondary Education Examination (ENEM). The main motivations for choosing medicine as an undergraduate course included personal and vocational skills, and the opportunity for personal fulfillment. The expectations of the academic training included working in a hospital context during the initial years of the course, and the desire to practice at different levels of health care, promoting recovery and rehabilitation. The postgraduation projects of the students included medical residency, professional competence, work-life balance, and becoming medical specialists/subspecialists. In terms of overall vision, the students declared that they were satisfied with their graduation course, pointing out just a few areas where the learning/teaching process was lacking. The majority of students in the first period (56\%) were unfamiliar with the DCNs of 2001 and 2014, and the majority of the students in the second period (54.8\%) reported knowing only the 2014 guidelines, with the college being indicated as the main source of information on the new DCNs. The students' expectations were, on the whole, in line with the principles, fundamentals and purposes of the medical training provided for in the new DCNs of the course in terms of the main competences and general abilities of the medical training, such as Integral Health Care, Health Education, and Health Management, as well as on the new dimensions addressed in these guidelines. However, some points of disagreement were observed, such as the lack of intention to become general practitioners or to focus their training on primary care, which is recommended in the guidelines; the intention to take care of their own mental health, also recommended in the new guidelines; and a certain resistance to the inclusion of new disciplines and new active learning methodologies as opposed to valuing traditional teaching methods.

\section{INTRODUÇÃO}

A graduação em Medicina, um dos cursos que mais forma profissionais a cada ano no Brasil ${ }^{1}$, tem duração média de seis anos e é, tradicionalmente, dividida em três fases (ou ciclos): básico, clínico e o internato ${ }^{2}$. Antes das mudanças curriculares, no ciclo básico, o estudante cursava disciplinas teóricas elementares para a formação médica, como fisiologia, anatomia, histologia e farmacologia. A fase clínica, por sua vez, permitia ao discente ampliar seu arcabouço teórico-técnico com um pequeno número de matérias práticas e incluía disciplinas como semiologia, pediatria, ginecologia, clínica médica e demais especialidades. Era no internato, então, que o acadêmico se via integralmente inserido no ambiente de prática, momento oportuno do curso para demonstrar todos os conceitos aprendidos. Esse modelo de formação perdurou muitos anos e foi amplamente questionado nas últimas décadas, resultando, assim, em grandes transformações curriculares ${ }^{3,4}$.

A formação do profissional médico é considerada um fator para a qualidade em saúde ${ }^{5}$, tornando-se uma das preocupações de instituições como a Organização Mundial da Saúde (OMS), Associação Brasileira de Educação Médica (Abem) e Organização Pan-Americana de Saúde (Opas), entre outras ${ }^{6,7}$. 
No século XIX, foi publicado o relatório Flexner, que conduziu por muitos anos o modelo de assistencialismo em saúde no País, voltado ao atendimento hospitalocêntrico. Tal paradigma instaurou um método reducionista de educação e possibilitou o desenvolvimento de escolas médicas que condicionavam o discente a um olhar exclusivamente anatomoclínico de seus pacientes. Com a criação do Sistema Único de Saúde (SUS), essa conformação profissional tornou-se inconsistente, uma vez que não era capaz de atender às demandas da população atendida pelo SUS, tendo em vista a inoperante personalidade generalista que esses médicos carregavam consigo ${ }^{3,5,8}$.

Posteriormente, com o aumento das críticas ao modelo de educação médica até então vivenciado no País, foram criadas em 2001 as primeiras Diretrizes Curriculares Nacionais para o Curso de Medicina9, documento que deveria guiar, a partir de então, a composição curricular das escolas médicas. Essas diretrizes propunham habilidades comuns a todos os cursos da área de saúde e habilidades específicas para a graduação em Medicina, representando uma revolução no ensino em saúde. Apesar disso, as DCN de 2001 deixavam a desejar quanto às transformações ocorridas paralelamente no SUS, porque, ainda que preconizassem a interdisciplinaridade necessária a uma visão integral no cuidado do paciente, era possível perceber a formação de médicos pouco habilidosos na prática clínica e pouco envolvidos com a visão histórico-social e humanística dos seus pacientes ${ }^{3,8,10}$.

Assim, em 2014 foram publicadas as novas DCN para o curso de Medicina. O novo documento, com 14 páginas, traz uma série de recomendações às quais as instituições superiores devem se adequar. Nele, aspectos socioculturais, humanísticos e biológicos do ser são considerados de forma interdisciplinar e multiprofissional ao longo dos anos de curso. As diretivas propostas nesse documento enfatizam a preocupação em formar médicos generalistas efetivos na abordagem ao paciente da atenção básica e da urgência/emergência e que sejam resolutivos na promoção e redução dos riscos em saúde. Em outras palavras, o documento prevê a formação de um profissional com habilidades gerais, crítico, reflexivo e ético, pronto para atuar em todos os níveis de atenção em saúde e que seja capaz de praticar ações de promoção, prevenção e reabilitação em saúde, respeitando sempre o direito do paciente à cidadania e à dignidade ${ }^{11}$.

Centradas em três grandes áreas - Atenção Integral à Saúde, Educação em Saúde e Gestão em Saúde -, as DCN propõem aos discentes o aprendizado de habilidades que permitam maior aptidão em lidar com os problemas da sociedade brasileira e da saúde pública, com ênfase na adequação às demandas do SUS e a programas como a Política Nacional de
Atenção Básica, por exemplo. Tudo isso por meio da articulação teórico-prática do projeto pedagógico do curso, objetivando a integração com conhecimentos de outras áreas, além do alinhamento às normas de instâncias governamentais, serviços oferecidos pelo SUS e por instituições prestadoras de serviços, oferecendo, assim, uma formação interprofissional e flexível que respeite as necessidades reais da população ${ }^{4,5,12,13}$.

As mudanças curriculares implementadas vêm para reforçar as diretrizes anteriores e possibilitar ao aluno, além da inserção antecipada no ambiente de prática, o convívio com o paciente em seu cotidiano, conhecendo a sua realidade por meio de visitas domiciliares, práticas de extensão, atividades de promoção, prevenção e recuperação do processo saúde-doença, empregando a visão biopsicossocial do ser. O conhecimento teórico-prático percorre então uma trajetória em "espiral", na qual o estudante, ao conviver desde os primeiros anos da graduação com profissionais e usufrutuários dos serviços em saúde, tem a oportunidade de associar os ensinamentos aprendidos em sala de aula com os absorvidos no ambiente de prática, construindo uma autonomia, reflexão e compreensão sobre a área médica que será consolidada no internato, no final do curso ${ }^{11}$.

As novas metodologias empregadas - como a aprendizagem baseada em problemas (ABP), o uso de portfólios e disciplinas preponderantemente de cunho prático - contribuem para transformar a visão do próprio discente acerca da graduação e a atuação do profissional médico ${ }^{8,10,14-17}$. A ABP, por exemplo, caracterizada como uma filosofia curricular, pode ser considerada uma solução para a melhoria da qualidade do processo de ensino-aprendizagem, funcionando como um eixo do aprendizado teórico do currículo médico, integrando as disciplinas, a teoria e a prática ${ }^{16}$. O emprego dessas novas metodologias também está previsto nas novas DCN. Conforme o Art. 29, parágrafo II, das DCN, a estrutura do curso de graduação em Medicina deve: "[...] utilizar metodologias que privilegiem a participação ativa do aluno na construção do conhecimento e na integração entre os conteúdos, assegurando a indissociabilidade do ensino, pesquisa e extensão" (Art. 29, Resolução CNE/ CES no 3, de 20 de junho de 2014, p. 12).

Pesquisas e projetos que procuram ampliar o conhecimento sobre as expectativas e concepções discentes durante a graduação em Medicina constituem estratégias primordiais e contínuas no processo de (re)pensar as propostas de aprendizagem, ensino e formação desenvolvidas nas escolas médicas brasileiras ${ }^{17}$. Poucos trabalhos foram encontrados na literatura a respeito das expectativas dos estudantes de Medicina frente a alterações nas grades curriculares, e, até o presente momento, nenhum trabalho foi publicado em relação às possíveis 
mudanças na percepção dos discentes após a efetivação das novas DCN.

Diante do exposto, este artigo busca avaliar as relações entre as expectativas dos discentes do primeiro ano do curso de Medicina de uma instituição de ensino superior (IES) sobre sua formação acadêmica e as novas Diretrizes Curriculares Nacionais do Curso de Medicina e em quais aspectos essas expectativas corroboram ou não os princípios, os fundamentos e as finalidades da formação em Medicina previstos nessas diretrizes.

\section{MATERIAL E MÉTODOS}

$\mathrm{O}$ estudo tem caráter transversal e descritivo, e abordagem quantitativa e qualitativa. O espaço físico definido para a execução do estudo foi uma instituição privada de ensino superior do Estado de Minas Gerais que, desde a implantação do curso de Medicina, em agosto de 2015, teve seu currículo inserido nos princípios, fundamentos e finalidades da formação em Medicina instituídos pelas novas DCN do curso de Medicina de 2014.

Os sujeitos do estudo foram os discentes maiores de 18 anos que se encontravam regularmente matriculados no primeiro ano do curso de Medicina (primeiro e segundo períodos) durante o segundo semestre de 2016. O instrumento de coleta de dados foi um questionário impresso autoaplicável e anônimo, que se espelhou em trabalhos que abordavam o mesmo tema ${ }^{2,4,6,7}$ e versava sobre questões como perfil do participante, expectativas em relação a sua formação acadêmica e profissional, e conhecimentos a respeito das novas DCN. Para isso, o questionário dividiu-se em quatro seções (I - Perfil do discente, II - Motivações iniciais e expectativas sobre a formação acadêmica, III - Planos e projetos futuros em relação à profissão, IV - Sobre as novas Diretrizes Curriculares Nacionais para o Curso de Medicina) e contou com 22 questões objetivas e seis questões discursivas.

A seção I continha sete perguntas, das quais quatro admitiam respostas discursivas, sendo o discente questionado quanto a: sua idade; cidade/estado de origem; qual graduação cursou e se esta foi ou não concluída (para os casos de discentes que já haviam ingressado em outra graduação); se o discente relatasse ter passado pelo processo de transferência, tendo como origem uma instituição que não havia aderido às novas DCN, qual a sua opinião quanto às mudanças sofridas no ensino e se estas eram positivas ou negativas. As perguntas objetivas versavam a respeito do gênero do discente, forma de ingresso na universidade e, em caso de transferência, se a instituição anterior havia aderido ou não às novas DCN.

A seção II contava com perguntas objetivas relacionadas às motivações dos discentes na escolha do curso, quais suas expectativas quanto a sua formação acadêmica e se suas expectativas com relação ao curso foram ou não atendidas até então. Uma pergunta discursiva sobre os motivos do não atendimento foi direcionada aos alunos que relataram não terem suas expectativas devidamente atendidas.

A seção III contou com uma pergunta objetiva relacionada às pretensões dos discentes após a formatura. E, na seção IV, foi analisado o conhecimento dos discentes acerca das mudanças curriculares realizadas a partir das novas DCN, a identificação destas mudanças e a existência de familiaridade com a diretriz antecessora. Uma questão discursiva foi direcionada aos discentes que declarassem conhecer as duas diretrizes curriculares, pedindo que descrevessem as mudanças mais significativas observadas entre os dois documentos.

Para a realização do estudo e em atendimento à orientação da Resolução 466/12 do Conselho Nacional de Saúde $(\mathrm{CNS})^{18}$, foi elaborado um Termo de Consentimento Livre e Esclarecido (TCLE). A declaração de aceitação da participação voluntária se firmou por meio da assinatura desse termo e só tiveram acesso ao questionário os participantes que, ao assinarem o TCLE, declararam estar cientes dos objetivos, dos riscos, dos benefícios e de suas garantias em participar da pesquisa. O trabalho foi submetido ao Comitê de Ética em Pesquisa (CEP) da Faculdade Dinâmica do Vale do Piranga (Fadip), sob o Certificado de Apresentação para Apreciação Ética (CAAE) 61866716.7.0000.8063 e aprovado pelo Parecer nํㅜ 1.876.667.

Os dados, após codificação, foram armazenados e processados utilizando-se o software Microsoft ${ }^{\circledR}$ Excel ${ }^{\circledR 2010}$, e a análise foi conduzida à luz da estatística descritiva ${ }^{19}$. As variáveis categóricas foram expressas em valores absolutos e percentuais. Na análise das questões discursivas, usamos o método de análise de conteúdo, que tem por objetivo a compreensão crítica das comunicações, em seu conteúdo tanto explícito quanto implícito, sendo operacionalizado por meio da leitura das respostas, categorização a partir dos termos afins, tabulação e descrição dos principais fatores de resposta. Os aspectos mais relevantes e mais incidentes foram apresentados também por meio da transcrição literal das respostas.

\section{RESULTADOS}

O questionário impresso foi respondido por 25 alunos do primeiro período e 31 do segundo período, correspondendo a uma taxa de adesão de 96,15\% e 96,87\%, respectivamente. Tal retorno da população estudada aproxima-se de um censo, garantindo confiabilidade e robustez ao banco de dados.

A Tabela 1 apresenta dados sobre o perfil dos discentes. Para os alunos do primeiro período, observou-se predomínio de discentes nascidos em cidades do interior do Estado de Mi- 


\begin{tabular}{|c|c|c|c|c|}
\hline $\begin{array}{r}\text { Ta bela } \\
\text { Perfil do dis }\end{array}$ & & & & \\
\hline & & $\begin{array}{l}\text { neiro } \\
\text { íodo }\end{array}$ & & $\begin{array}{l}\text { indo } \\
\text { odo }\end{array}$ \\
\hline Variável & $\mathbf{n}$ & $\%$ & $\mathrm{n}$ & $\%$ \\
\hline Naturalidade & & & & \\
\hline Capital da UF onde estuda & 0 & 0,0 & 0 & 0,0 \\
\hline Cidade do interior da UF onde estuda & 20 & 80,0 & 28 & 90,3 \\
\hline Em cidade de outra UF & 5 & 20,0 & 3 & 9,7 \\
\hline Sexo & & & & \\
\hline Masculino & 10 & 40,0 & 13 & 41,9 \\
\hline Feminino & 15 & 60,0 & 18 & 58,1 \\
\hline Idade & & & & \\
\hline $18-20$ anos & 11 & 44,0 & 16 & 51,6 \\
\hline $21-22$ anos & 8 & 32,0 & 8 & 25,8 \\
\hline 23-24 anos & 3 & 12,0 & 2 & 6,5 \\
\hline $25-26$ anos & 2 & 8,0 & 2 & 6,5 \\
\hline$>27$ anos & 1 & 4,0 & 3 & 9,6 \\
\hline Forma de ingresso na instituição & & & & \\
\hline Vestibular & 24 & 96,0 & 21 & 67,8 \\
\hline Mudança de curso & 0 & 0,0 & 0 & 0,0 \\
\hline Transferência de outra instituição & 0 & 0,0 & 6 & 19,3 \\
\hline Fies ou ProUni & 0 & 0,0 & 1 & 3,2 \\
\hline Não responderam & 1 & 4,0 & 3 & 9,7 \\
\hline $\begin{array}{l}\text { Número de vestibulares que realizou } \\
\text { contando com a aprovação na institu }\end{array}$ & & & & \\
\hline Um & 1 & 4,0 & 4 & 12,9 \\
\hline Dois & 2 & 8,0 & 2 & 6,5 \\
\hline Três & 4 & 16,0 & 3 & 9,7 \\
\hline Quatro & 3 & 12,0 & 1 & 3,2 \\
\hline Cinco & 3 & 12,0 & 1 & 3,2 \\
\hline Mais de cinco & 11 & 44,0 & 18 & 58,0 \\
\hline Não responderam & 1 & 4,0 & 2 & 6,5 \\
\hline $\begin{array}{l}\text { Número de vezes que prestou o Enem } \\
\text { até a aprovação na instituição }\end{array}$ & & & & \\
\hline Um & 0 & 0,0 & 2 & 6,5 \\
\hline Dois & 4 & 16,0 & 7 & 22,5 \\
\hline Três & 12 & 48,0 & 9 & 29,0 \\
\hline Quatro & 4 & 16,0 & 7 & 22,5 \\
\hline Cinco & 1 & 4,0 & 3 & 9,7 \\
\hline Mais de cinco & 3 & 12,0 & 2 & 6,5 \\
\hline Não responderam & 1 & 4,0 & 1 & 3,2 \\
\hline Alunos que já cursaram outra graduaça & & & & \\
\hline Não concluíram & 4 & 16,0 & 1 & 4,0 \\
\hline Concluíram & 0 & 0,0 & 3 & 12,0 \\
\hline
\end{tabular}

nas Gerais (80\%), pertencentes ao sexo feminino (60\%) e na faixa etária de 18 a 20 anos (44\%). A principal forma de ingresso na instituição foi o vestibular (96\%), com predomínio de discentes que prestaram mais de cinco vestibulares até o ingresso na instituição (44\%) e que prestaram o Enem por três vezes (48\%). Neste mesmo período, quatro alunos (16\%) já haviam cursado outra graduação, mas não chegaram a concluí-la. Para os alunos do segundo período, observou-se predomínio de discentes nascidos em cidades do interior do estado (90,3\%), pertencentes ao sexo feminino (58,1\%) e faixa etária de 18 a 20 anos (51,6\%). A principal forma de ingresso na instituição foi o vestibular (67,8\%); prevaleceram os discentes que prestaram mais de cinco vestibulares até o ingresso na instituição (58\%) e que prestaram o Enem por três vezes (29\%). Neste período, quatro alunos já haviam cursado outra graduação, e três deles (12\%) a concluíram.

Seis alunos do segundo período responderam que vieram transferidos de outra instituição (Tabela 1). A eles foi perguntado se suas instituições de origem já haviam aderido ou não às novas DCN. Desse total, quatro declararam que sim $(66,7 \%)$, e os outros dois alunos não responderam (Tabela 2). Diante disso, não houve resultados válidos referentes ao item do questionário que indagava: "Como você se sente frente a uma nova instituição que se adaptou às novas Diretrizes Curriculares Nacionais? Você vê isso como uma mudança positiva ou negativa? Quais as principais diferenças que você pôde perceber?", uma vez que a questão era dirigida apenas aos estudantes transferidos de instituições nas quais as novas diretrizes ainda não haviam sido instituídas.

\begin{tabular}{|c|c|c|c|c|}
\hline \multicolumn{5}{|l|}{ Pertil da } \\
\hline \multirow[b]{2}{*}{ Variável } & \multicolumn{2}{|c|}{$\begin{array}{l}\text { Primeiro } \\
\text { período }\end{array}$} & \multicolumn{2}{|c|}{$\begin{array}{l}\text { Segundo } \\
\text { período }\end{array}$} \\
\hline & n & $\%$ & $\mathrm{n}$ & $\%$ \\
\hline \multicolumn{5}{|c|}{$\begin{array}{l}\text { Adesão da instituição de origem às DCN } \\
\text { de } 2014\end{array}$} \\
\hline Aderidas & 0 & 0,0 & 4 & 66,7 \\
\hline Não aderidas & 0 & 0,0 & 0 & 0,0 \\
\hline Parcialmente aderidas & 0 & 0,0 & 0 & 0,0 \\
\hline Não responderam & 0 & 0,0 & 2 & 33,3 \\
\hline
\end{tabular}

A Tabela 3 indica que os alunos do primeiro período tiveram como principal motivação para a escolha da Medicina como curso de graduação as aptidões pessoais e vocacionais $(15,9 \%)$ e que os alunos do segundo período tiveram a possibilidade de realização pessoal $(15,3 \%)$ como principal motivação. As motivações secundárias destacadas pelos alunos do primeiro período foram possibilidade de contribuir com a sociedade (14,3\%); possibilidade de realização pessoal $(13,4 \%)$ e desejo de ajudar e servir ou trabalhar com pessoas $(12,6 \%)$; já as motivações secundárias dos alunos do segundo período foram aptidões pessoais e vocacionais; possibilidade de contribuir com a sociedade e identificação com o curso (todas com 
$11,4 \%$ ), além do desejo de ajudar e servir às pessoas ou trabalhar com pessoas $(10,8 \%)$ e gosto pela área biológica $(10,2 \%)$.

Em relação às expectativas sobre a formação acadêmica, os alunos do primeiro e segundo períodos esperam se inserir num contexto hospitalar nos anos iniciais do curso (19,8\% e 21,6\%); atuar no processo saúde-doença em seus diferentes níveis de atenção, com ações de promoção, prevenção, recuperação e reabilitação à saúde (17,8\% e 20,7\%); tornar-se um profissional multidisciplinar (15,7\% e 14,4\%); cuidar da própria saúde física e mental e buscar o próprio bem-estar como cidadão e como médico (14,6\% e 12,4\%); e conhecer sobre a sociedade, a história e o ambiente que cerca o paciente $(11,4 \%$ e 13,4\%), respectivamente. Apenas dois alunos, um de cada turma, ainda escolheram a opção outra alternativa e especificaram o desejo de fazer residência e de se inserir no Projeto Médicos Sem Fronteiras.

Nove alunos do primeiro período (36\%) e quatro do segundo $(12,9 \%)$ imaginavam que o curso seria da forma como tinha sido até o momento da pesquisa; 12 alunos (48\%) e 19 alunos $(61,3 \%)$ do primeiro e segundo períodos, respectivamente, imaginavam o curso parcialmente da forma como tinha sido; e três alunos do primeiro período (12\%) e oito do segundo $(25,8 \%)$ não imaginavam que o curso seria da forma como tinha sido até o momento da pesquisa.

As expectativas com relação ao curso foram totalmente atendidas para $56 \%$ dos alunos do primeiro período e para $32,2 \%$ dos alunos do segundo período. Quarenta por cento dos alunos do primeiro período e $45,2 \%$ dos alunos do segundo tiveram suas expectativas parcialmente atendidas, e para $22,6 \%$ dos alunos do segundo período as expectativas com relação ao curso não foram atendidas.

Os principais pontos de descontentamento indicados pelos estudantes do primeiro período que tiveram suas expectativas com relação ao curso parcialmente atendidas foram as deficiências no aprendizado de disciplinas que julgavam importantes para a sua formação e o sentimento de falta de apoio da coordenação com relação às queixas por eles destacadas.

Para os estudantes do segundo período que tiveram suas expectativas parcialmente atendidas ou não atendidas, os principais pontos foram o julgamento de que algumas disciplinas que eles consideram não serem tão importantes para sua formação estariam sobrecarregando a carga horária de disciplinas que consideram fundamentais e a falta de didática de alguns professores, o que comprometeria o processo de ensino-aprendizagem mais efetivo em disciplinas do ciclo básico.

No que concerne aos planos e projetos futuros associados à profissão (Tabela 4), observou-se que a maioria dos alunos do

\begin{tabular}{|c|c|c|c|c|}
\hline $\begin{array}{r}\text { TABEL } \\
\text { Motivações iniciai } \\
\text { sobre a formaçâ }\end{array}$ & 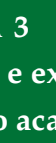 & $\begin{array}{l}\text { ectat } \\
\text { êmic }\end{array}$ & & \\
\hline & & $\begin{array}{l}\text { iro } \\
\text { do }\end{array}$ & & \\
\hline Variável & $\mathrm{n}$ & $\%$ & $\mathrm{n}$ & $\%$ \\
\hline Principal/principais motivações par & esco & er o cl & de & dicina* \\
\hline Aptidões pessoais e vocacionais & 19 & 15,9 & 20 & 11,4 \\
\hline Possibilidade de realização pessoal & 16 & 13,4 & 27 & 15,3 \\
\hline $\begin{array}{l}\text { Possibilidade de contribuir com a } \\
\text { sociedade }\end{array}$ & 17 & 14,3 & 20 & 11,4 \\
\hline $\begin{array}{l}\text { Desejo de ajudar e servir pessoas } \\
\text { ou trabalhar com pessoas }\end{array}$ & 15 & 12,6 & 19 & 10,8 \\
\hline $\begin{array}{l}\text { Empregabilidade ou diversidade } \\
\text { de áreas de atuação }\end{array}$ & 8 & 6,7 & 13 & 7,4 \\
\hline Bons salários/status social & 13 & 10,9 & 17 & 9,6 \\
\hline Identificação com o curso & 13 & 10,9 & 20 & 11,4 \\
\hline Curiosidade científica & 0 & 0 & 9 & 5,1 \\
\hline Gosto pela área biológica & 7 & 5,9 & 18 & 10,2 \\
\hline Influência de terceiros & 3 & 2,5 & 3 & 1,7 \\
\hline Fantasia ou sonho desde a infância & 7 & 5,9 & 9 & 5,1 \\
\hline $\begin{array}{l}\text { Opção pessoal sem outras } \\
\text { explicações }\end{array}$ & 1 & 0,8 & 1 & 0,6 \\
\hline Outras(s) motivação(motiv & 0 & 0,0 & 0 & 0,0 \\
\hline
\end{tabular}

Expectativas dos discentes em relação a sua formação acadêmica* Se tornar um profissional

multidisciplinar

Se inserir num contexto hospitalar nos anos iniciais do curso

$15 \quad 15,7 \quad 14$

Cuidar da própria saúde física e

mental e buscar o próprio bem-

estar como cidadão e como médico

Ter a formação voltada para a

atenção primária à saúde

Conhecer sobre a sociedade, a

história e o ambiente que cerca o

paciente

Se inserir num contexto hospitalar

nos anos finais do curso

$19+100$

$19 \quad 19,8 \quad 21 \quad 21,6$

Atuar no processo de saúde-

doença em seus diferentes

$\begin{array}{lllll}\text { níveis de atenção, com ações de } & 17 & 17,8 & 20 & 20,7\end{array}$

promoção, prevenção, recuperação

e reabilitação à saúde

Atuar como partícipe do processo

ensino-aprendizagem

Outra(s) expectativa(s)

$14 \quad 14,6 \quad 12$

12,4

Imaginava o curso da forma como tem sido até o momento

$\begin{array}{lllll}\text { Sim } & 9 & 36,0 & 4 & 12,9\end{array}$

$\begin{array}{lllll}\text { Parcialmente } & 12 & 48,0 & 19 & 61,3\end{array}$

$\begin{array}{lllll}\text { Não } & 3 & 12,0 & 8 & 25,8\end{array}$

$\begin{array}{lllll}\text { Não responderam } & 1 & 4,0 & 0 & 0,0\end{array}$

Expectativas com relação ao curso

$\begin{array}{lllll}\text { Totalmente atendidas } & 14 & 56,0 & 10 & 32,2\end{array}$

$\begin{array}{lllll}\text { Parcialmente atendidas } & 10 & 40,0 & 14 & 45,2\end{array}$

$\begin{array}{lllll}\text { Não foram atendidas } & 0 & 0,0 & 7 & 22,6\end{array}$

$\begin{array}{lllll}\text { Não responderam } & 1 & 4,0 & 0 & 0,0\end{array}$

*Nesta pergunta era permitido escolher mais de uma alternativa; logo, as porcentagens apresentadas dizem respeito ao total de alunos respondentes por alternativa. 
primeiro e segundo períodos pretende fazer residência médica após a formatura (22,4\% e 25,2\%, respectivamente). As demais pretensões mais citadas pelos alunos do primeiro período foram conciliar trabalho e qualidade de vida $(19,4 \%)$, tornar-se um médico especialista/subespecialista e buscar competência profissional, ambas com $(17,4 \%)$, e compatibilizar saúde pública e privada (16,3\%). Para os alunos do segundo período, as demais pretensões foram buscar competência profissional $(22,4 \%)$, conciliar trabalho e qualidade de vida $(17,8 \%)$ e se tornar um médico especialista/subespecialista (15,9\%).

\begin{tabular}{lccccc}
\multicolumn{3}{c}{ TA B ELA 4 } & & & \\
\multicolumn{4}{c}{ Planos e projetos futuros relativos à profissão } \\
& $\begin{array}{l}\text { Primeiro } \\
\text { período }\end{array}$ & $\begin{array}{c}\text { Segundo } \\
\text { período }\end{array}$ \\
\cline { 2 - 6 } & n & $\%$ & n & $\%$ \\
Variável & 17 & 17,4 & 17 & 15,9 \\
Pretensões dos discentes após a formatura* & & & & \\
Se tornar um médico especialista/ & & & & \\
subespecialista & 1 & 1,0 & 2 & 1,9 \\
Ser um médico generalista & 1 & 1,0 & 3 & 2,8 \\
Trabalhar exclusivamente para o SUS & 16 & 16,3 & 12 & 11,2 \\
Compatibilizar saúde pública e privada & 5 & 5,1 & 2 & 1,9 \\
Trabalhar conforme as demandas do & & & & \\
mercado & 19 & 19,4 & 19 & 17,8 \\
Conciliar trabalho e qualidade de vida & 17 & 17,4 & 24 & 22,4 \\
Buscar competência profissional & 22 & 22,4 & 27 & 25,2 \\
Fazer residência médica & 0 & 0,0 & 1 & 0,9 \\
Muito cedo para opinar & 0 & 0,0 & 0 & 0,0 \\
Outra alternativa &
\end{tabular}

*Nesta pergunta era permitido escolher mais de uma alternativa; logo, as porcentagens apresentadas dizem respeito ao total de alunos respondentes por alternativa.

As informações a respeito das novas DCN do curso de Medicina e as expectativas dos discentes em relação a estas diretrizes são apresentadas na Tabela 5. Pela análise dos resultados, observa-se que a maioria dos alunos do primeiro período (56\%) desconhece as DCN de 2001 e 2014, e que a maioria dos alunos do segundo período conhece apenas as diretrizes de 2014 (54,8\%).

Dos alunos respondentes do primeiro período, somente um declarou ter conhecimento sobre as DCN de 2001 e 2014. Dez alunos (40\%) responderam conhecer as DCN de 2014 e não se obteve resposta nesse período sobre o conhecimento exclusivo das DCN de 2001. Sete alunos do segundo período $(22,6 \%)$ responderam conhecer as duas DCN, cinco responderam não ter conhecimento sobre as $\mathrm{DCN}$ e não se obteve resposta nesse período sobre o conhecimento exclusivo das DCN de 2001.

Aos alunos que responderam ter conhecimento sobre as duas DCN foi direcionada a seguinte pergunta: "Na sua opi- nião, o que muda no curso de Medicina em relação às diretrizes curriculares de 2001 e às novas diretrizes de 2014?". O único aluno do primeiro período que declarou ter conhecimento de ambas as DCN destacou que o fato de o estudante ter contato com pacientes já no início do curso contribui enquanto experiência: "E11: o contato com pacientes já no primeiro período na atenção primária nos possibilita mais experiências".

Para os alunos do segundo período respondentes a essa pergunta, a mudança percebida com relação às duas DCN foi o aprendizado voltado para a humanização da relação médico-paciente: "E27: O curso ficou mais humanizado, a gente convive com o paciente desde o início e tem matérias específicas para treinar e aprender sobre a relação médico-paciente".

A principal fonte de informação para o conhecimento das DCN de 2014 foi a faculdade (48\% e 80,6\% no primeiro e segundo períodos, respectivamente). Quarenta por cento dos alunos do primeiro período consideram que a mudança curricular realizada em 2014 é muito importante para a sua formação e 48,4\% dos alunos do segundo período consideram a mudança importante.

Na opinião dos alunos do primeiro período, as principais competências e habilidades gerais da formação médica previstas nas novas DCN são: Atenção Integral à Saúde (19\%), Educação em Saúde (18\%) e Gestão em Saúde e tomada de decisões, ambas com $17 \%$. Na opinião desses alunos, as principais dimensões abordadas nas novas DCN são "interação multiprofissional e pesquisas científicas" (14,7\%), seguidas por "novas metodologias a serem discutidas"; "atenção às necessidades de saúde coletiva" e "a importância da comunicação verbal e não verbal", todas com 11,9\%.

Para os alunos do segundo período, as principais competências e habilidades gerais da formação médica previstas nas novas DCN são: Atenção Integral à Saúde (23,7\%), Educação em Saúde (16,7\%) e Gestão em Saúde e Comunicação (15,8\% para ambas). E as principais dimensões abordadas nestas DCN são: "interação multiprofissional" (15,1\%), seguida por "pesquisas científicas"; " a importância da comunicação verbal e não verbal" e "atenção às necessidades de saúde coletiva", todas com $12,1 \%$.

Na pergunta: "Qual (quais) das opções você considera fundamental na formação médica?" era permitida a escolha de mais de uma alternativa e solicitava-se que fossem numeradas em 1, 2 ou 3 de acordo com o grau de importância que o aluno atribuía às opções escolhidas. Para o primeiro período, a opção considerada pela maioria como fundamental foi a Atenção Integral à Saúde (26,5\%), que foi também a área considerada com maior grau de importância. As opções Gestão em Saúde e Educação em Saúde foram igualmente consideradas 


\begin{tabular}{|c|c|c|c|c|}
\hline \multicolumn{5}{|c|}{$\begin{array}{c}\text { TABELA } 5 \\
\text { Sobre as Novas Diretrizes Curriculares } \\
\text { Nacionais para o Curso de Medicina }\end{array}$} \\
\hline \multirow[b]{2}{*}{ Variável } & \multicolumn{2}{|c|}{$\begin{array}{l}\text { Primeiro } \\
\text { período }\end{array}$} & \multicolumn{2}{|c|}{$\begin{array}{l}\text { Segundo } \\
\text { período }\end{array}$} \\
\hline & n & $\%$ & n & $\%$ \\
\hline \multicolumn{5}{|c|}{$\begin{array}{l}\text { Conhecimento sobre as Diretrizes Curriculares Nacionais do Curso } \\
\text { de Medicina de } 2001 \text { e de } 2014\end{array}$} \\
\hline Conhecem as duas diretrizes & 1 & 4,0 & 7 & 22,6 \\
\hline Não conhecem nenhuma das diretrizes & 14 & 56,0 & 5 & 16,1 \\
\hline Só conhecem as novas diretrizes de 2014 & 10 & 40,0 & 17 & 54,8 \\
\hline Só conhecem as diretrizes de 2001 & 0 & 0,0 & 0 & 0,0 \\
\hline Não responderam & 0 & 0,0 & 2 & 6,5 \\
\hline
\end{tabular}

Fonte de conhecimento a respeito das Diretrizes Curriculares

Nacionais do Curso de Medicina de 2014

$\begin{array}{lcccc}\text { Faculdade } & 12 & 48,0 & 25 & 80,6 \\ \text { Internet } & 3 & 12,0 & 1 & 3,2 \\ \text { Amigos } & 0 & 0,0 & 1 & 3,2 \\ \text { Não conheço estas diretrizes } & 9 & 36,0 & 2 & 6,5 \\ \text { Outros meios. Quais? } & 0 & 0,0 & 0 & 0,0\end{array}$

Importância da mudança curricular realizada em 2014 para a sua

formação

$\begin{array}{lcccc}\text { Sem importância } & 0 & 0,0 & 0 & 0,0 \\ \text { Pouco importante } & 0 & 0,0 & 4 & 12,9 \\ \text { Importante } & 5 & 20,0 & 15 & 48,14 \\ \text { Muito importante } & 10 & 40,0 & 6 & 19,3 \\ \text { Não sei opinar } & 9 & 36,0 & 4 & 12,9 \\ \text { Não responderam } & 1 & 4,0 & 2 & 6,5\end{array}$

Que competências e habilidades gerais da formação médica estão previstas nas novas $\mathrm{DCN}^{*}$ ?

Atenção Integral à Saúde

Administração e Gerenciamento

$19 \quad 19,0 \quad 27 \quad 23,7$

Tomada de decisões

$\begin{array}{llll}5 & 5,0 & 7 & 6,1\end{array}$

Comunicação

$17 \quad 17,0 \quad 12 \quad 10,5$

Liderança

Gestão em Saúde

Educação permanente

$14 \quad 14,0 \quad 18 \quad 15,8$

$\begin{array}{llll}3 & 3,0 & 4 & 3,5\end{array}$

$17 \quad 17,0 \quad 18 \quad 15,8$

Educação em Saúde

$\begin{array}{llll}7 & 7,0 & 9 & 7,9\end{array}$

$18 \quad 18,0 \quad 19 \quad 16,7$

Qual(quais) das novas dimensões a seguir foram abordadas nas novas Diretrizes Curriculares Nacionais do Curso de Medicina de 2014*

$\begin{array}{lllll}\text { Pesquisas científicas } & 16 & 14,7 & 21 & 12,1\end{array}$

$\begin{array}{llllll}\text { Biodiversidade e sustentabilidade } & 8 & 7,3 & 15 & 8,7\end{array}$

$\begin{array}{lllll}\text { A importância da comunicação verbal e } \quad 13 & 11,9 & 21 & 12,1\end{array}$

não verbal

$\begin{array}{lllll}\text { Tomada de decisões } & 6 & 5,5 & 11 & 6,5\end{array}$

$\begin{array}{lllll}\text { Gestão do cuidado } & 10 & 9,2 & 18 & 10,5\end{array}$

$\begin{array}{lllll}\text { Interação multiprofissional } & 16 & 14,7 & 26 & 15,1\end{array}$

$\begin{array}{llllll}\text { Processo de aprendizagem } & 8 & 7,3 & 10 & 5,8\end{array}$

$\begin{array}{lllll}\text { Novas metodologias a serem discutidas } \quad 13 & 11,9 & 18 & 10,5\end{array}$

Atenção às necessidades de saúde coletiva $\quad 13 \quad 11,9 \quad 21 \quad 12,1$

$\begin{array}{llllll}\text { Medicina baseada em evidências } & 6 & 5,5 & 11 & 6,5\end{array}$

Qual(quais) das opções você considera fundamental na formação médica**

Atenção Integral à Saúde

Gestão em Saúde

Educação em Saúde

Todas

$\begin{array}{cccc}14 & 26,5 & 20 & 29,0 \\ 13 & 24,5 & 19 & 27,5 \\ 13 & 24,5 & 21 & 30,4 \\ 13 & 24,5 & 9 & 13,0\end{array}$

(continua)

\begin{tabular}{|c|c|c|c|c|}
\hline \multirow[b]{2}{*}{ Variável } & \multicolumn{2}{|c|}{$\begin{array}{c}\text { Primeiro } \\
\text { período }\end{array}$} & \multicolumn{2}{|c|}{$\begin{array}{c}\text { Segundo } \\
\text { período }\end{array}$} \\
\hline & $\mathrm{n}$ & $\%$ & n & $\%$ \\
\hline
\end{tabular}

Sua visão em relação ao curso e à Formação médica mudou com a implantação das novas diretrizes

Sim, para melhor

Sim, para pior

Mudou parcialmente

Não mudou

Não sei opinar

$\begin{array}{cccc}9 & 36,0 & 5 & 16,1 \\ 1 & 4,0 & 7 & 22,6 \\ 5 & 20,0 & 8 & 25,8 \\ 0 & 0,0 & 3 & 9,7 \\ 8 & 32,0 & 4 & 12,9 \\ 2 & 8,0 & 4 & 12,9\end{array}$

Não responderam

Qual a importância das disciplinas incluídas a partir das novas

História e formação da sociedade brasileira), na formação médica

Sem importância

Pouco importante

Importante

Muito importante

Não sei opinar

$\begin{array}{cccc}0 & 0,0 & 4 & 12,9 \\ 5 & 20,0 & 8 & 25,8 \\ 9 & 36,0 & 9 & 29,0 \\ 9 & 36,0 & 5 & 16,1 \\ 0 & 0,0 & 3 & 9,7 \\ 2 & 8,0 & 2 & 6,5\end{array}$

Não responderam

$\begin{array}{ccc}2 & 8,0 & 2 \\ \text { ens e Tecnologias de }\end{array}$

Qual a importância das disciplinas Ling
Comunicação I e II, na formação médica

Sem importância

Pouco importante

Importante

Muito importante

$\begin{array}{cccc}1 & 4,0 & 4 & 12,9 \\ 5 & 20,0 & 8 & 25,8 \\ 8 & 32,0 & 6 & 19,3 \\ 10 & 40,0 & 10 & 32,2 \\ 0 & 0,0 & 1 & 3,2 \\ 1 & 4,0 & 2 & 6,5\end{array}$

Não responderam

rendizado Baseado em

Opinião sobre a importância do método Aprendizado Baseac
Problemas (ABP) utilizado em alguns cursos de Medicina

Sem importância

$\begin{array}{llll}0 & 0,0 & 0 & 0,0\end{array}$

Pouco importante

$8,0 \quad 4 \quad 12,9$

Importante

Muito importante

Não sei opinar

Não gosto desse método

$20,0 \quad 11 \quad 35,5$

$\begin{array}{llll}8 & 32,0 & 7 & 22,6\end{array}$

se método $\quad 3 \quad 12,0 \quad 4 \quad 12,9$

Opinião sobre a importância do método Medicina Baseada em

Evidências (MBE), utilizado em alguns cursos de Medicina

$\begin{array}{lllll}\text { Sem importância } & 0 & 0,0 & 0 & 0,0\end{array}$

$\begin{array}{lllll}\text { Pouco importante } & 2 & 8,0 & 1 & 3,2\end{array}$

Importante $\quad \begin{array}{llll}10 & 40,0 & 6 & 19,3\end{array}$

$\begin{array}{lllll}\text { Muito importante } & 5 & 20,0 & 5 & 16,1\end{array}$

$\begin{array}{lllll}\text { Não sei opinar } & 6 & 24,0 & 11 & 35,5\end{array}$

$\begin{array}{lllll}\text { Não gosto desse método } & 0 & 0,0 & 0 & 0,0\end{array}$

$\begin{array}{lllll}\text { Não responderam } & 2 & 8,0 & 8 & 25,8\end{array}$

Opinião sobre a importância do método tradicional de ensino e avaliação para o curso de Medicina

Sem importância

Pouco importante

Importante

Muito importante

Não sei opinar

Não responderam

$\begin{array}{cccc}0 & 0,0 & 0 & 0,0 \\ 1 & 4,0 & 1 & 3,2 \\ 10 & 40,0 & 14 & 45,1 \\ 11 & 44,0 & 13 & 41,9 \\ 1 & 4,0 & 2 & 6,5 \\ 2 & 8,0 & 1 & 3,2\end{array}$

*Nesta pergunta, era permitido escolher mais de uma alternativa; logo, as porcentagens apresentadas dizem respeito ao total de alunos respondentes por alternativa.

**Nesta pergunta, era permitido escolher mais de uma alternativa e solicitava-se que fossem numeradas em 1, 2 ou 3 segundo o grau de importância que o aluno atribuía às opções escolhidas. 
como fundamentais na formação médica $(24,5 \%)$, sendo que o grau de importância maior foi atribuído para a Educação em Saúde. Para o segundo período, a área de formação considerada pela maioria como fundamental foi a Educação em Saúde $(30,4 \%)$. Já a área para a qual foi atribuído o maior grau de importância foi a Atenção Integral à Saúde, seguida da opção Educação em Saúde.

Com a implementação das novas diretrizes, a visão em relação ao curso e à formação médica mudou para melhor na opinião de $36 \%$ dos discentes do primeiro período, embora uma parcela (32\%) tenha afirmado não saber opinar. Para o segundo período, a visão em relação ao curso e à formação médica foi alterada parcialmente $(25,8 \%)$ ou se alterou para pior $(22,6)$.

Os alunos do primeiro período (36\%) consideram muito importantes/importantes (mesmo número de respondentes) na formação médica as disciplinas incluídas a partir das novas DCN, como Saúde, Sociedade e Ambiente I e II (Ecologia Médica, História e Formação da Sociedade Brasileira) e 40\% consideram muito importantes as disciplinas Linguagens e Tecnologias de Comunicação I e II. Consideram muito importante (32\%) o método Aprendizado Baseado em Problemas (ABP) utilizado em alguns cursos de Medicina e consideram importante (40\%) o método Medicina Baseada em Evidências (MBE); eles consideram, ainda, o método tradicional de ensino e avaliação como sendo muito importante (44\%).

Na opinião de $29,0 \%$ dos alunos do segundo período, as disciplinas Saúde, Sociedade e Ambiente I e II (Ecologia Médica, História e Formação da Sociedade Brasileira) são importantes na formação médica, e 32,2\% consideraram as disciplinas Linguagens e Tecnologias de Comunicação I e II muito importantes. O método ABP foi considerado importante por $35,5 \%$ e a maioria não soube opinar $(35,5 \%)$ ou não respondeu $(25,8 \%)$ sobre o método MBE; o método tradicional de ensino e avaliação foi considerado importante por $45,1 \%$.

Vale ressaltar que a afirmativa "Não gosto deste método" era uma das opções de resposta para os métodos ABP e MBE. Nenhum discente disse não gostar do método MBE e 12\% dos discentes do primeiro período e $12,9 \%$ dos discentes do segundo período disseram não gostar do método ABP.

\section{DISCUSSÃO}

A estrutura curricular, a relação professor-aluno, a atuação do corpo docente, a qualidade de ensino, a fragmentação do saber, a prática distante da teoria, a metodologia de ensino-aprendizagem e a infraestrutura são fatores que podem constituir problemas durante a formação do estudante de Medicina ${ }^{15}$. Nesse contexto, o estudo das mudanças curriculares e das expectativas geradas nos discentes recém-ingressos é de fundamental importância para a condução de seu desenvolvimento com excelência. Isto é reforçado por Fiorotti et al. ${ }^{7}$ ao afirmarem que o conhecimento sobre os alunos de Medicina e sobre o que eles pensam acerca da sua formação é o primeiro passo para as futuras intervenções educacionais terem sucesso.

Em nosso estudo, discentes do primeiro ano do curso de Medicina de uma instituição privada mineira foram avaliados quanto as suas expectativas de formação acadêmica e à relação dessas expectativas com as novas DCN do curso de Medicina, implementadas em 2014. O perfil dos estudantes dessa instituição é composto principalmente por discentes do sexo feminino, nascidos em cidades do interior de Minas Gerais, na faixa etária de 18 a 20 anos, que tiveram o vestibular como forma de ingresso na instituição e que prestaram mais de cinco vestibulares e três vezes o Enem.

As motivações iniciais para a escolha da graduação em Medicina relatadas pelos entrevistados coincidem, de forma geral, com os impulsos primários observados em outros estudos com acadêmicos de Medicina ${ }^{2,6,7,10,15,17}$. De acordo com os resultados obtidos, foi possível depreender que algumas perspectivas dos estudantes vão ao encontro das DCN, como pôde ser observado quando os entrevistados, questionados sobre suas motivações iniciais, escolheram, em sua maioria, alternativas que versavam a respeito de aptidões vocacionais, contribuição com a sociedade, possibilidade de realização pessoal, desejo de ajudar e servir pessoas e gosto pela área biológica. Tendo em vista a crescente preocupação com uma humanização maior na relação médico-paciente, infere-se que os futuros médicos que tiveram seus impulsos iniciais consoantes com os princípios críticos, humanos e reflexivos citados no documento construirão de forma mais fácil o perfil profissional esperado.

Do mesmo modo, em relação às expectativas quanto à formação acadêmica, predominaram esperar se inserir em contextos hospitalares nos anos iniciais do curso; atuar no processo saúde-doença em diferentes níveis de atenção, promovendo a recuperação e a reabilitação da saúde em todos os âmbitos; e a perspectiva de se tornar um profissional multidisciplinar. Todas essas concepções vão ao encontro dos propósitos preconizados pelas DCN como essenciais na formação médica, posto que, durante a formação, o ambiente de prática é primordial para o aperfeiçoamento das habilidades e, depois de formado, o profissional deverá ser capaz de considerar o paciente em todas as suas dimensões, respeitando os direitos humanos e as diversidades culturais e atuando como membro de uma equipe e agente ativo nos processos de Educação e Gestão da Saúde. 
Nas questões discursivas, os estudantes tiveram a oportunidade de descrever as principais mudanças percebidas em relação às novas DCN e de apresentar suas opiniões. Os resultados mostram que as alterações percebidas diziam respeito à humanização do curso e à introdução de disciplinas que não faziam parte da grade tradicional. Eles se mostraram receptivos à discussão no curso sobre a importância da comunicação verbal e não verbal e a relevância de conhecer as diversidades culturais presentes no País. Nessas questões puderam também expressar o desapontamento em relação a algumas particularidades do curso e da instituição. As respostas giraram em torno de assuntos como estrutura, falta de didática de alguns professores e extensa carga horária. As falhas descritas pouco diziam respeito às $\mathrm{DCN}$ e se assemelhavam às perspectivas apontadas por discentes de outras instituições em pesquisas sobre expectativas em relação ao curso ${ }^{15,17,20,21,22,}$.

A novidade deste estudo foi averiguar se os alunos possuíam conhecimento sobre as Diretrizes Curriculares de 2001 e 2014 e como percebiam o impacto das novas DCN na sua formação médica. Observamos o desconhecimento de ambas as DCN pela maioria dos discentes do primeiro período, enquanto a maioria dos discentes do segundo período só conhecia as DCN de 2014. Uma possível explicação para esse desconhecimento, em especial sobre as DCN de 2001, pode ser o reflexo da falta de busca de informação sobre as diretrizes antes do ingresso na faculdade. Com o ingresso na faculdade, esta passa a dar ao aluno subsídios para o conhecimento sobre as novas diretrizes. Isto foi corroborado pelos dados obtidos, que apontaram ser a faculdade a principal fonte de conhecimento em relação às DCN de 2014. No tocante às competências e habilidades, estes discentes relatam compreender que a Atenção Integral à Saúde, a Educação em Saúde e a Gestão em Saúde são indispensáveis ao desenvolvimento técnico de um bom médico, sendo elas as áreas nas quais a formação do graduado em Medicina se desdobrará. Ao serem questionados sobre as principais dimensões abordadas nas diretrizes, a maioria dos discentes escolheu alternativas que continham aspectos verdadeiramente citados e discutidos nas novas DCN, como o desenvolvimento de pesquisas científicas, a importância da comunicação verbal e não verbal, a gestão do cuidado, a interação multiprofissional, atenção às necessidades de saúde coletiva e novas metodologias a serem discutidas.

No entanto, foi possível perceber que em alguns tópicos as expectativas dos entrevistados não coincidiram com as novas DCN e que para alguns a visão com relação ao curso e à formação médica após a implementação das novas diretrizes mudou apenas parcialmente ou foi percebida como um impacto negativo na graduação. Como ponto de discordância entre as expectativas dos discentes e os princípios das novas DCN, podemos citar que cuidar da própria saúde física e mental e alcançar o bem-estar como médico e cidadão é a expectativa de $46 \%$ do total de respondentes da pesquisa. Contudo, nas novas diretrizes não constam incisos que pormenorizem as questões referentes à própria saúde do discente em comparação às diretrizes anteriores, que especificavam claramente como um dos deveres dos egressos das escolas médicas do País a atenção com a própria saúde mental, física e social. Além disso, mais de $60 \%$ dos alunos declararam a pretensão de se tornar médicos especialistas/subespecialistas, em oposição a apenas 5,3\%, que expressaram o desejo de se formar generalistas, um dos focos das DCN de 2014. Apenas oito dos 56 alunos participantes têm expectativa de ter uma formação voltada para a atenção primária, embora a Resolução no 3 de junho de 2014 seja bem enfática ao definir a importância de formar profissionais capazes de atuar nos diferentes níveis de atenção, sobretudo na atenção primária, onde se encontram as maiores demandas por bons profissionais.

Algumas disciplinas introduzidas a partir das novas diretrizes despertaram certa resistência dos alunos, que chegaram a considerar que estas estariam desviando a carga horária das disciplinas que consideram fundamentais na formação médica. As metodologias ativas de aprendizagem como a ABP foram consideradas importantes, e a MBE parece ainda não ter sido bem compreendida, uma vez que cerca de 30\% dos alunos não souberam opinar a seu respeito. Em relação ao método tradicional de ensino, $42,8 \%$ dos alunos o consideraram muito importante, evidenciando certa preferência por metodologias já conhecidas por eles.

A ABP foi concebida no Canadá nos anos 1960 na Universidade de McMaster e se espalhou pelo mundo, inclusive no Brasil, contando na atualidade com expressivo número de instituições ${ }^{23}$. Gomes e Rego ${ }^{14}$, em 2011, fizeram uma revisão de literatura com base em artigos publicados nos vinte anos anteriores ao da pesquisa. Esses autores sustentam que os resultados encontrados não comprovaram os ganhos cognitivos esperados pela $\mathrm{ABP}$; e que a diferenciação do perfil do egresso resultou de mudanças curriculares em que se usaram outras estratégias de mudança, como a inserção no serviço de saúde e na comunidade desde o início do curso, além da inserção da estrutura curricular com base na $\mathrm{ABP}$, o que pode funcionar como viés importante da avaliação, demonstrando a insuficiência da mudança pedagógica isolada como resposta a uma formação médica capaz de aliar competências técnicas e ético-humanísticas ${ }^{14}$. 


\section{CONSIDERAÇÕES FINAIS}

O objetivo deste trabalho foi avaliar se as expectativas dos discentes do primeiro ano do curso de Medicina de uma instituição de ensino superior em relação à sua formação acadêmica corroboravam ou não os princípios, fundamentos e finalidades da formação em Medicina previstos nas novas Diretrizes Curriculares Nacionais do Curso de Medicina.

Por se tratar de um documento recente, por existirem poucos trabalhos sobre as novas DCN e provavelmente pelo fato de a busca de informações sobre as diretrizes se dar apenas com o ingresso do discente na faculdade, alguns alunos não apresentaram conhecimento profundo do tema. Contudo, ainda assim, nossos resultados apontaram uma relação bem estabelecida entre as expectativas dos estudantes e os princípios previstos nas novas diretrizes. As perspectivas dos discentes, em sua maioria, foram ao encontro dos princípios anunciados pelas diretrizes no que tange às principais competências e habilidades gerais da formação médica, bem como sobre as novas dimensões abordadas nestas diretrizes. Vale ressaltar, no entanto, pontos de desencontro, como, por exemplo, a baixa intenção dos discentes de se tornarem profissionais generalistas e terem sua formação voltada para a atenção primária. Depreende-se ainda que as expectativas, além de corroborarem, em sua maioria, as novas diretrizes, estão de acordo com a Lei 2.488/2011 sobre as Políticas Nacionais de Atenção Básica, que estabelecem uma série de atribuições esperadas do profissional médico.

Este trabalho traz à literatura dados inéditos sobre a percepção dos estudantes em relação às novas disciplinas introduzidas, às mudanças ocorridas no perfil profissional esperado e às novas DCN em geral. Sugere-se que instituições de ensino superior abordem temas como os que envolvem a saúde mental e o bem-estar do estudante, que não foram discutidos nas novas diretrizes; que novas pesquisas sejam realizadas com o intuito de enriquecer a literatura sobre o tema; e que as escolas de Medicina do País desenvolvam novas metodologias para que as novas DCN sejam efetivamente empregadas e aceitas pelos alunos e para que eventuais lacunas sejam preenchidas.

\section{REFERÊNCIAS}

1. MS. Demografia Médica no Brasil. Cenários e Indicadores de Distribuição. São Paulo: Conselho Regional de Medicina do Estado de São Paulo: Conselho Federal de Medicina, 2013. (Relatório)

2. Cardoso Filho FAB, Magalhães JF, da Silva KML, Pereira ISSD. Perfil do Estudante de Medicina da Universidade do Estado do Rio Grande do Norte (UERN), 2013. Rev Bras Educ Med 2015;39(1)32-40.
3. Costa JRB, Romano VF, Costa RR, Gomes AP, Alves LA, Siqueira-Batista R. A Transformação Curricular e a Escolha da Especialidade Médica. Rev Bras Educ Med 2014;38(1)47-58.

4. Franco CAGS, Cubas MR, Franco RS. Currículo de Medicina e as Competências Propostas pelas Diretrizes Curriculares. Rev Bras Educ Med 2014 ;38(2)221-230.

5. Moretti-Pires RO, Bueno SMV. Freire e formação para o Sistema Único de Saúde: o enfermeiro, o médico e o odontólogo. Acta Paul Enferm 2009. 22(4);439-444.

6. Ferreira RA, Peret Filho LA, Goulart EMA, Valadão MMA. O estudante de medicina da Universidade Federal de Minas Gerais: perfil e tendências. Rev Ass Med Brasil 2000 46(3)224-231.

7. Fiorotti KP, Rossoni RR, Miranda AE. Perfil do Estudante de Medicina da Universidade Federal do Espírito Santo, 2007.Rev Bras Educ Med 2010;34(3)355-362.

8. Silveira JLGC, Rodrigues KF, Shishido M, Moraes P. Pesquisa e Extensão em Saúde e a Aprendizagem nos Níveis Cognitivo e Afetivo. Rev Bras Educ Med 2015;39(4)550557.

9. Brasil. Ministério da Educação. Conselho Nacional de Educação. Câmara de Educação Superior. Resolução CNE/CES no 4 de 7 de novembro de 2001. Institui diretrizes curriculares nacionais do curso de graduação em Medicina. Diário Oficial da União. Brasília, 9 nov. 2001; Seção 1, p.38.

10. Gomes MPC, Ribeiro VMB, Monteiro DM, Leher EMT, Louzada RCR. O Uso de Metodologias Ativas no ensino de graduação nas Ciências Sociais e da saúde - avaliação dos estudantes. Ciência \& Educação 2010;16(1)181-198.

11. Brasil. Ministério da Educação. Conselho Nacional de Educação. Câmara de Educação Superior. Resolução №. 3 de 20 de junho de 2014. Institui diretrizes curriculares nacionais do curso de graduação em Medicina e dá outras providências. Diário Oficial da União, Brasília, 23 jun. 2014; Seção 1, p. 8-11.

12. Garcia MAA, Souza Pinto ATBC, Odoni APC, Longhi BS, Machado LI, Linek MDS, et al. A Interdisciplinaridade Necessária à Educação Médica. Rev Bras Educ Med 2007; 31(2)147-155.

13. Gomes AP, Rego S. Paulo Freire: Contribuindo para Pensar Mudanças de Estratégias no Ensino de Medicina. Rev Bras Educ Med 2014;38(3)299-313.

14. Gomes AP, Rego S. Transformação da Educação Médica: É Possível Formar um Novo Médico a partir de Mudanças no Método de Ensino- Aprendizagem? Rev Bras Educ Med 2011;35(4)557-566. 
15. Trindade LMDF, Vieira MJ. Curso de Medicina: motivações e expectativas de estudantes iniciantes. Rev Bras Educ Med 2009;33(4)542-554.

16. Penaforte J. John Dewey e as raízes filosóficas da aprendizagem baseada em problemas. In: Mamede S, Penaforte J, Schmidt H, Caprara A, Tomaz JB, Sá H, org. Aprendizagem baseada em problemas: anatomia de uma nova abordagem educacional. Fortaleza: Escola de Saúde Pública/ São Paulo: Editora Hucitec, 2001. p. 49-78.

17. Dini OS, Batista NA. Graduação e prática médica: expectativas e concepções de estudantes de Medicina do $1^{\circ}$ ao $6^{\circ}$ ano. Rev Bras Educ Med. [online]. 2004. 28(3) [capturado 13 mar 2017];198-203.

18. Brasil. Conselho Nacional de Saúde. Ministério da Saúde. Diretrizes e Normas regulamentadoras de pesquisas envolvendo Seres Humanos. Resolução N 466, de 12 de Dezembro de 2012. 1-12, 2012

19. Polit DF, Beck CT, Hungler BP. Fundamentos de pesquisa em enfermagem: métodos, avaliação e utilização. 5. ed. Porto Alegre: Artmed; 2004.

20. Neves N, Lemos K, Bitencourt A, Neves FS, Nunes C, Neville I, et al. Expectativa versus Realidade na Formação Médica: o (Des)encanto do Estudante de Medicina. Gaz Med Bahia 2006;76(2)20-28.

21. Arruda, PCV. As relações entre alunos, professores e pacientes. In: Millan LR, De Marco OLN, Rossi E, Arruda PCV. O Universo Psicológico do futuro médico: vocação, vicissitudes e perspectivas. São Paulo: Casa do Psicólogo; 1999. p.43-73.

22. Macedo DH, Batista NA. O Mundo do Trabalho durante a Graduação Médica: a Visão dos Recém-Egressos. Rev Bras Educ Med 2011;35(1)44-51.

23. Rowan C, Mc Court BA, Brecke S. Midwives reflection on their educational programme: a traditional or problem based learning approach? Midwifery 2009; 25(2). 213-222.

\section{CONTRIBUIÇÃO DOS AUTORES}

Maria Alexandra de Carvalho Meireles: concebeu o estudo, contribuiu para o seu design e para a coleta de dados supervisionados, analisou e interpretou os dados, bem como escreveu o manuscrito. Cássia do Carmo Pires Fernandes: contribuiu no conteúdo intelectual do manuscrito, no desenho e interpretação dos dados e revisão da escrita do manuscrito. Lorena Souza e Silva: contribuiu no conteúdo intelectual do manuscrito, no desenho, na coleta e interpretação de dados e revisão da escrita do manuscrito.

\section{CONFLITO DE INTERESSES}

Os autores declaram não haver conflito de interesses.

\section{ENDEREÇO PARA CORRESPONDÊNCIA}

Maria Alexandra de Carvalho Meireles

Faculdade Dinâmica do Vale do Piranga - Departamento de Medicina

Rua G, 205 - Lote 11

Paraíso - Ponte Nova

CEP 35430-324 - MG

E-mail: marimeirelles27@gmail.com

Cássia do Carmo Pires Fernandes

Instituto Federal de Educação, Ciência e Tecnologia de Minas Gerais

Campus Avançado de Ponte Nova

Rua Carlos Gomes, 76

Esplanada - Ponte Nova

CEP 35430-031 - MG

E-mail: cassia.pires@ifmg.edu.br

Lorena Souza e Silva

Faculdade Dinâmica do Vale do Piranga

Departamento de Medicina

Rua G, 205 - Lote 11

Paraíso - Ponte Nova

CEP 35430-324 - MG

E-mail: lorenanupeb@gmail.com 